\title{
In vitro antiviral activity of styrylpyrone derivative-incorporated formulations against Herpes simplex virus type-1
}

\author{
Adibah Ahamad Bahtiar, Norefrina Shafinaz Md Nor and Nazlina Ibrahim \\ School of Biosciences and Biotechnology, Faculty of Science and Technology, Universiti Kebangsaan Malaysia, 43600 \\ Bangi, Selangor, Malaysia. \\ Email: nazlina@ukm.edu.my
}

Received 6 January 2016; Received in revised form 6 March 2016; Accepted 7 March 2016

\begin{abstract}
Aims: This study was aimed to evaluate in vitro antiviral activity of topical formulations incorporated with a styrylpyrone derivative (SPD) against Herpes Simplex Virus type 1 (HSV-1).

Methodology and results: Two types of SPD-incorporated formulations (ointment and gel) were tested for their antiviral activity against HSV-1 clinical strain using plaque reduction assay on Vero cells. The antiviral activity was determined based on the percentage of plaque reduction occurred between treatment and control (non-treated infected cells). In this study, 10\% SPD-gel (SPD $=0.004 \mathrm{mg}$ ) and 20\% SPD-ointment (SPD = $0.003 \mathrm{mg}$ ) showed plaque reduction percentage of $87 \%$ and $79 \%$ respectively. Further evaluation on the ointment base, gel base (formulation without SPD) demonstrated less than $10 \%$ of antiviral activity while pure SPD at $0.0025 \mathrm{mg}$ showed $81 \%$ of plaque reduction. These results indicated that the antiviral activity observed in both SPD-incorporated ointment and gel was mainly due to SPD regardless of formulation components. Furthermore, the antiviral activities observed in both SPD-incorporated products were also in agreement with the antiviral activity observed in pure SPD.

Conclusion, significance and impact study: SPD-incorporated products retained the antiviral activity and can further be tested in animal model.
\end{abstract}

Keywords: HSV-1, antiviral, Goniothalamus umbrosus, styrylpyrone derivative

\section{INTRODUCTION}

Current strategy to fight HSV-1 infection is by using commercial drug such as acyclovir (ACV). The drug reacts as DNA chain terminator during DNA synthesis, where viral thymidine kinase (TK) followed by cell host kinases phosphorylate ACV into competitive inhibitor of viral DNA polymerase (De Clercq, 2004). Viral strains resistant to acyclovir have emerged due to mutation in TK or DNA polymerase (Hussin et al., 2013). Other alternative such as foscarnet is also facing resistance issue (Saijo et al., 2005). This scenario has encouraged scientists to develop alternative drugs which depend on different antiviral pathway.

Styrylpyrone derivative (SPD) is one of the bioactive compounds isolated from Goniothalamus umbrosus. Its potent antiviral property against HSV-1 was by inducing apoptosis and cell cycle arrest in infected cells (Md. Nor, 2015) and virucidal activity (Moses et al., 2014). However, the effect of the compound in vivo has yet to be studied. Prior to in vivo study of this compound, the antiviral efficacy of topical formulation should be tested in vitro, since some components in the formulation might interfere with the biological activity of the active ingredient
(Georgetti et al., 2006). Thus, the aim of this study is to evaluate the antiviral activity of SPD-incorporated formulations against HSV-1.

\section{MATERIALS AND METHODS}

\section{Preparation of topical formulation}

Two types of SPD-incorporated products were used in this study which were ointment-based and gel-based formulation. Preparation of SPD crystal isolated from root extract of Goniothalamus umbrosus was done through crystallization process based on Jewers et al. (1972). The purity of isolated SPD was evaluated using gas chromatography-mass spectrometry (GC-MS). For SPDincorporated ointment, it consisted of $20 \%$ (w/w) SPD, $50 \%$ blackseed oil and $80 \%$ (w/w) white petroleum jelly $\left(V^{2}\right.$ aseline $\left.{ }^{\mathrm{TM}}\right)$. For SPD-incorporated gel, it consisted of $10 \%(w / w)$ SPD, 1\% (w/w) soy-lecithin (Shaklee ${ }^{\Theta}$ ), 20\% (v/w) methyl benzoate (Nacalai Tesque, Japan) 4\% (v/w) Tween 80 (Sigma-Aldrich, USA), 2\% (w/w) hydroxypropyl methylcellulose (Lotioncrafter ${ }^{\circledR}$, USA) and deionized water. Both formulations were prepared based on Allen et al. (2011) with several modifications in terms of the 
volume and ratio of the components in the formulation. Both formulations were stored at room temperature.

Preparation of both formulations for cytotoxicity and antiviral activity was done based on Dorwal (2012) with modifications of ethanol being used as the solvent. Briefly, SPD was extracted from ointment or gel by mixing $\sim 10 \mathrm{mg}$ of respective formulation with absolute ethanol and vortexed for $15 \mathrm{~min}$. Undissolved components were separated by centrifugation at $4000 \mathrm{rpm}$ for $5 \mathrm{~min}$ (Microfuge 16, Beckman Coulter, USA). This step was repeated twice. The extracted SPD was diluted into several concentrations for cytotoxicity testing. Final concentration for ethanol was less than $1 \%$.

\section{Cytotoxicity screening}

Screening on cytotoxicity of extracted SPD and respective formulation bases were conducted using 3-(4,5Dimethylthiazol-2-yl)-2,5 diphenyltetrazolium bromide (MTT) based on Mossman (1983). First, Vero cells at $2 \times 10^{5}$ cells $/ \mathrm{mL}$ was seeded in 96 -well flat bottom plate supplemented with Dulbecco's Modified Eagle Medium (DMEM), 5\% fetal bovine serum (FBS) and incubated overnight. Upon confluency, cells were treated with extracted SPD which was already serial diluted in DMEM supplemented with $5 \%$ FBS. Cells with media only were used as negative control and empty well filled with media was used as blank. Cells were further incubated for 48 hours. After incubation, medium was decanted and replaced with $40 \mu \mathrm{L}$ MTT plus $100 \mu \mathrm{L}$ DMEM and cells were incubated for $3 \mathrm{~h}$. Formazan crystals formed after incubation were dissolved using 100\% dimethyl sulphoxide (DMSO) and the optical absorbance was taken at $545 \mathrm{~nm}$ using Chromate (Awareness Technology Inc, USA). Cell viability was determined using the formula below. Non-linear regression was done to calculate $50 \%$ cytotoxic concentration $\left(\mathrm{CC}_{50}\right)$.

$$
\begin{aligned}
& \text { Cell viability } \\
& \text { percentage }
\end{aligned}=\frac{O D_{\text {test well }}-O D_{\text {blank }}}{O D_{\text {negative control }}-O D_{\text {blank }}} \times 100
$$

\section{Antiviral test}

Plaque reduction assay for antiviral activity was based on Souza et al. (2008) with modification in the virus concentration. Briefly, $2 \times 10^{5}$ cells $/ \mathrm{mL}$ of Vero cells was seeded on 12-well plates supplemented with DMEM and $5 \%$ FBS and incubated overnight. After overnight incubation, cells were infected with 50 PFU (plaque forming unit) of HSV-1. After two hours adsorption period, infected cells were treated with 3 different concentrations for each formulation (with and without SPD). Pure SPD at $0.0025 \mathrm{mg}(12.5 \mu \mathrm{M})$ was used as experimental control while ACV at $0.001 \mathrm{mg}(5 \mu \mathrm{M})$ was used as positive control. Each well was overlaid with culture media (DMEM+ 5\% FBS+ $1 \%$ methylcellulose) and further incubated for another $48 \mathrm{~h}$. After $48 \mathrm{~h}$ incubation or until visible plaques appeared, all cells were stained with crystal violet and plaques were counted under microscope. Percentage of plaque reduction was calculated based on formula below:

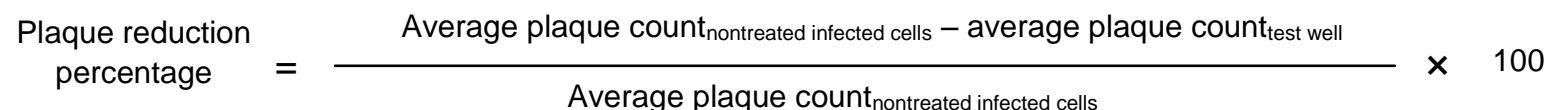

\section{Statistical analysis}

One-way ANOVA or student t-test was conducted to analyse significant difference where difference was considered significant if $p$ value $<0.05$.

\section{RESULTS}

Cytotoxicity screening showed $\mathrm{CC}_{50}$ value for ointment and gel base were $0.84 \mathrm{mg} / \mathrm{mL}$ and $14.0 \mathrm{mg} / \mathrm{mL}$ respectively, while for SPD extracted from 20\%-SPD ointment and $10 \%$-SPD gel showed $\mathrm{CC}_{50}$ value of 0.09 $\mathrm{mg} / \mathrm{mL}$ and $0.30 \mathrm{mg} / \mathrm{mL}$ respectively (Figure 1 ).

Since determination of what concentration to be used in antiviral activity is based on $\mathrm{CC}_{50}$, therefore, different concentration used between SPD-ointment and SPD-gel was due to different $\mathrm{CC}_{50}$ value. For antiviral activity, both SPD-incorporated ointment and gel showed a significant antiviral activity against HSV-1. As depicted in Figure 2A and $2 \mathrm{~B}$, the formulation bases only showed less than $15 \%$ plague reduction percentage at their highest non-toxic concentration. On the other hand, both SPD-incorporated ointment and gel showed high plaque reduction percentage at $86 \%$ and $98 \%$ respectively (Figure $3 \mathrm{~A}$ and
3B). The actual SPD concentration in each formulation was also found to exert similar antiviral activity showed by purified form. For ointment, 20\% SPD-ointment (SPD = $0.003 \mathrm{mg}$ ) showed $79 \%$ plaque reduction while $10 \%$ SPDgel $(S P D=0.004 \mathrm{mg})$ showed $87 \%$ plaque reduction. Pure SPD at $0.0025 \mathrm{mg}$ showed $81 \%$ plaque reduction (Figure 2C), which is in accordance with previous report where SPD at $0.0025 \mathrm{mg}(12.5 \mu \mathrm{M})$ was not toxic and showed high antiviral activity (Md Nor and Ibrahim, 2011). Further analysis showed in Table 1 suggested that the antiviral activity was still significant even after subtraction with the antiviral activity exerted by formulation base.

\section{DISCUSSION}

The original purpose of conducting antiviral screening for SPD-incorporated formulation is to evaluate whether SPD still retain the antiviral activity even after being mixed into a mixture of chemical components. The antiviral activities observed in both SPD-incorporated ointment and gel was in agreement with activity observed in pure SPD. In comparison to ACV, the activity of SPD was slightly lower than ACV. This is expected as ACV mode of action is specifically targeting viral DNA polymerase activity, which 
A

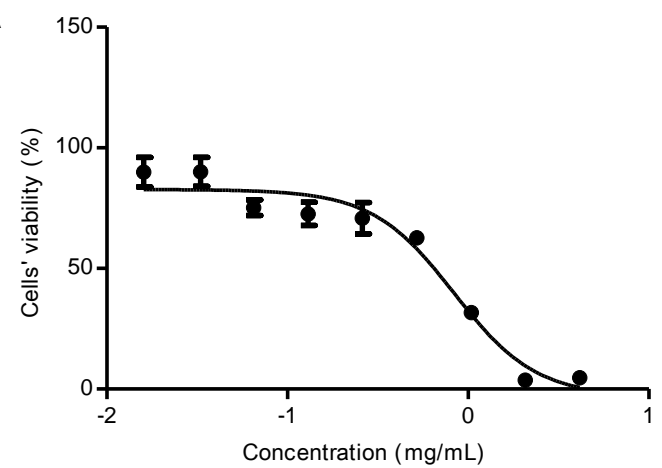

C

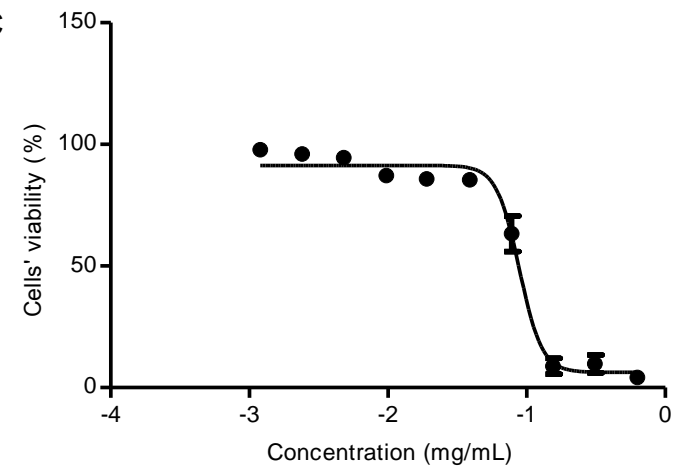

B

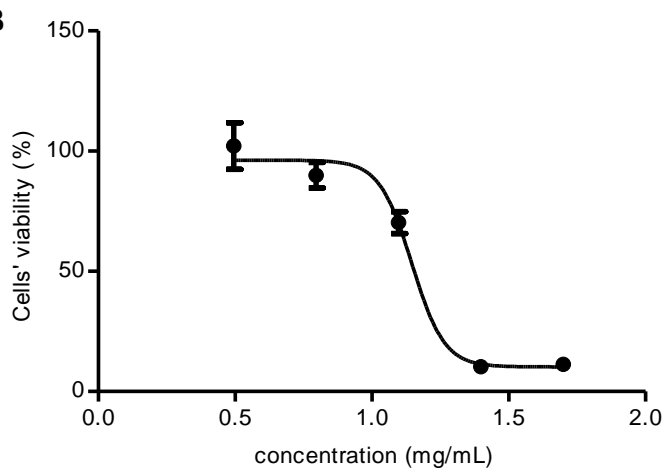

D

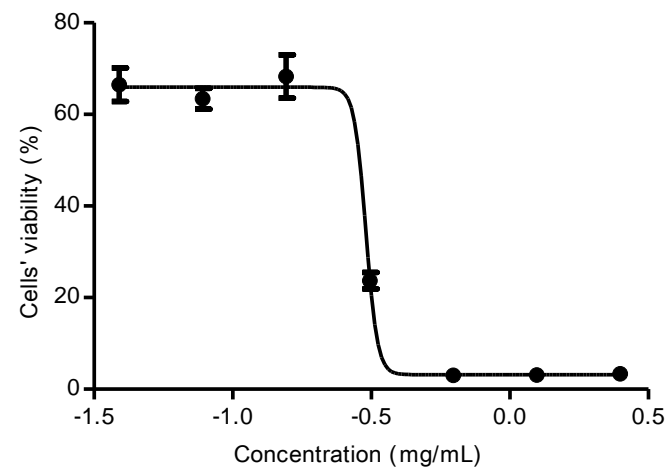

Figure 1: Cytotoxicity screening of formulation bases and SPD extracted from formulation. A, ointment base; B, gel base; C, 20\% SPD-ointment and D, 10\% SPD-gel. SD bar represented the data from at least three independent experiments.
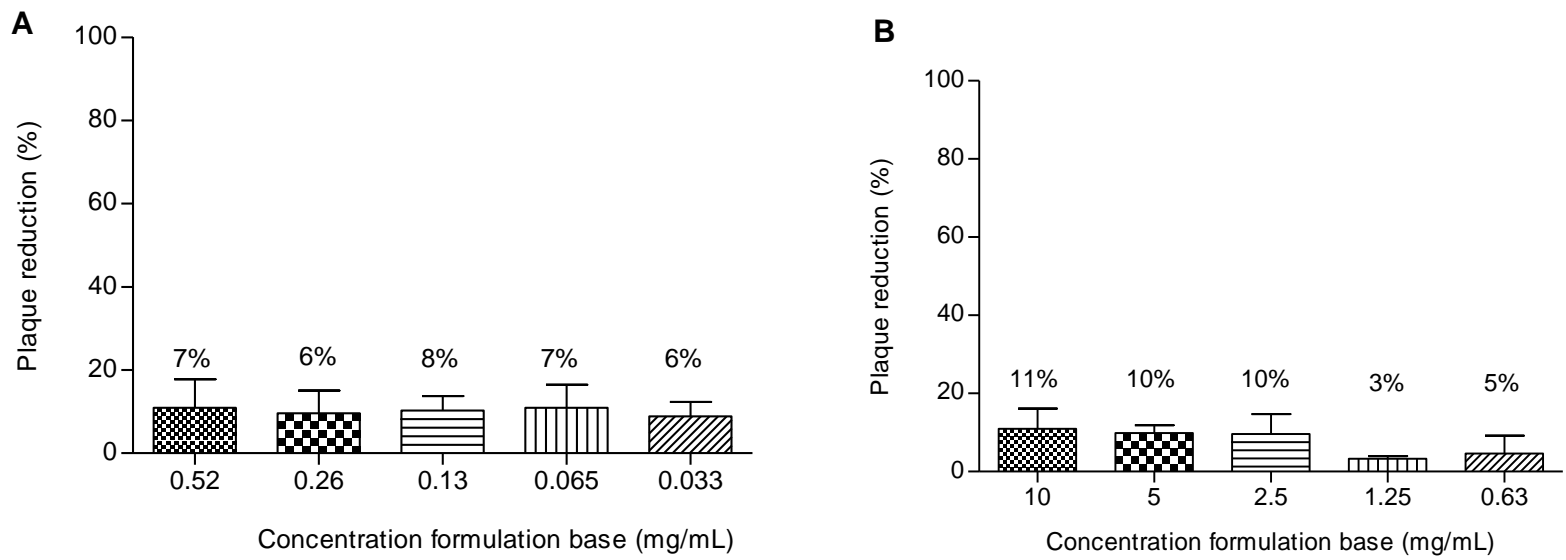

Figure 2: Plaque reduction percentage of formulation bases where $A$, ointment base and $B$, gel base. 
A

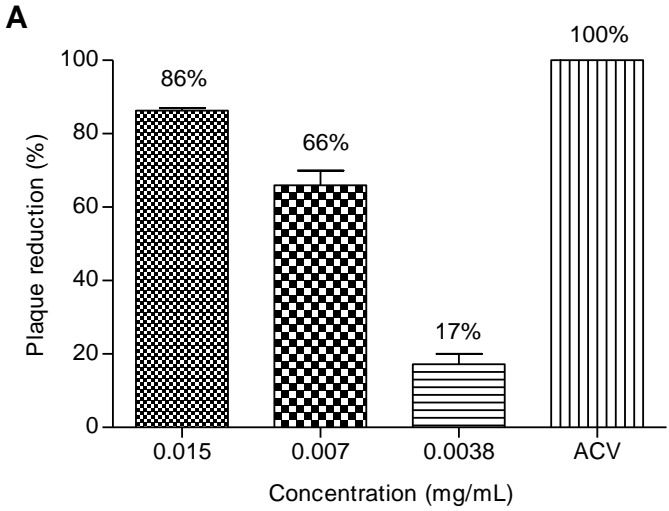

B

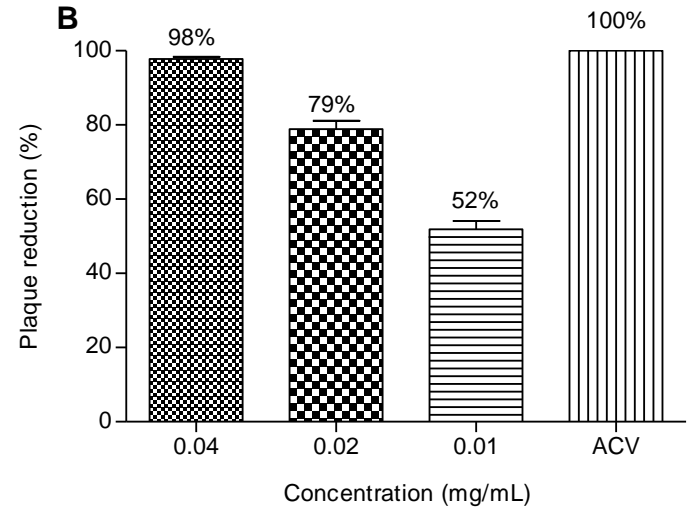

C

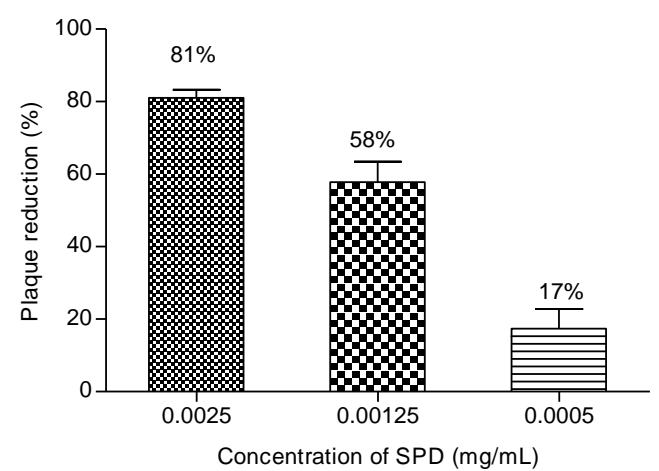

Figure 3: Plaque reduction percentage for SPD-incorporated formulations and pure SPD (crystal form) where A, 20\% SPD-incorporated ointment; B, 10\% SPD-incorporated gel and C, pure SPD. Concentration of positive control (ACV) was $0.001 \mathrm{mg} / \mathrm{mL}$. SD bar represented the data from at least three independent experiments.

Table 1: SPD concentration and plaque reduction percentage after normalized with baseline activity. SD bar represented the data from at least three independent experiments.

\begin{tabular}{lcc}
\hline & SPD conc. in formulation $(\mathrm{mg} / \mathrm{mL})$ & $\begin{array}{c}\text { \% Plaque reduction formulation - \% plaque reduction } \\
\text { formulation base }\end{array}$ \\
\hline $\begin{array}{l}20 \% \text { ointment } \\
(0.015 \mathrm{mg} / \mathrm{mL})\end{array}$ & 0.003 & $86-7=79 \%$ \\
$10 \% \mathrm{gel}$ & 0.004 & $98-11=87 \%$ \\
$(0.04 \mathrm{mg} / \mathrm{mL})$ & & $98 \%$ \\
\hline
\end{tabular}

Note: SPD concentration was calculated based on original stock of $10 \mathrm{mg}$ formulation. $20 \%$ ointment consist of $2 \mathrm{mg}$ SPD, therefore SPD in $0.015 \mathrm{mg}$ formulation is $(0.015 \mathrm{mg} \times 2 \mathrm{mg} \mathrm{SPD} / 10 \mathrm{mg}) .10 \%$ gel consist of $1 \mathrm{mg}$ SPD, therefore SPD in $0.04 \mathrm{mg}$ formulation is $(0.04 \mathrm{mg} \times 1 \mathrm{mg} \mathrm{SPD} / 10 \mathrm{mg})$. SD bar represented the data from at least three independent experiments.

is known to be one of the most efficient antiviral targets (Allaudeen et al., 1982). However, virus can easily mutate which leads to resistance towards ACV (Christophers et al., 1998) and also to other alternatives namely Foscarnet and Cidofovir (Burrel et al., 2013). Antiviral drug with mechanism that does not directly targets the virus has less chances to cause virus mutation and become resistant to drug (Muller and Krausslich, 2009). Since SPD mechanism was not directly targeting the virus where it induces cell cycle arrest and apoptosis in virusinfected cells (Md Nor, 2015), SPD has a good potential as a new antiviral drug and is worth to be further studied.
Baseline antiviral activity observed in both formulation bases were expected since some of the components used in the formulation itself have antiviral potential, such as black seed oil against murine cytomegalovirus and Hepatitis C virus (Salem and Hossain, 2000; Barakat et al., 2013) and lecithin against Hepatitis A virus (Ramadan and Asker, 2009). However, ability of SPD-incorporated ointment and SPD-incorporated gel to retain the antiviral activity after subtraction with antiviral in respective formulation bases proved the activity shown by both ointment and gel were not masked by the formulation components. 
Since both 20\%-SPD ointment and 10\%-SPD gel retained the antiviral activity, both formulations will be further studied in vivo. Preparation of two different types of formulations was intended to test suitability of each formulation as topical antiviral. Emollient effect exerted by ointment and its immiscibility with water will allow it to remain on the skin without being easily washed out. This may help in prolonged exposure to the drug (Bajaj et al., 2012). Meanwhile, gel has a non- greasy feature which is easily spread thus allowing it to thoroughly cover the affected area (Ajazuddin et al., 2013). In conclusion, both SPD-incorporated ointment and gel were proven to retain the antiviral activity against HSV-1 and should be evaluated in vivo.

\section{ACKNOWLEDGEMENT}

The authors would like to thank UKM in supporting research activities and Ministry of Science, Technology and Innovation for financial support granted throughout the study (Sciencefund: 02-01-02-SF0759, GUP 2014058, GGPM-2012-108).

\section{REFERENCES}

Ajazuddin, A. A., Khinchariya, G. S., Patel, R. J., Giri, T. K. and Tripathi, D. K. (2013). Recent expansions in an emergent novel drug delivery technology: Emulgel. Journal of Controlled Release 171, 122-132.

Allaudeen, H. S., Descamps, J. and Sehgal, R. K. (1982). Mode of action of acyclovir triphosphate on herpesviral and cellular DNA polymerases. Antiviral Research 2, 123-133.

Allen, L. V., Popovich, N. G. and Ansel, H. C. (2011). Ansel's pharmaceutical dosage forms and drug delivery systems. Lippincott Williams \& Wilkins, Baltimore. pp. 273-278.

Bajaj, S., Singla, D. and Sakhuja, N. (2012). Stability testing of pharmaceutical products. Journal of Applied Pharmaceutical Science 2(3), 129-138.

Barakat, E. M. F., Wakeel, L. M. E. and Hagag, R. S. (2013). Effects of Nigella sativa on outcome of hepatitis C in Egypt. World Journal of Gastroenterology 19(16), 2529-2536.

Burrel, S., Aime, C., Hermet, L., Ait-Arkoub, Z., Agut, H. and Boutolleau, D. (2013). Surveillance of herpes simplex virus resistance to antivirals: A 4-year survey. Antiviral Research 100, 365-372.

Christophers, J., Clayton, J., Craske, J., Collins, P., Trowbridge, M., Darby, G. and Ward, R. (1998). Survey of resistance of Herpes Simplex Virus to acyclovir in Northwest England. Antimicrobial Agents and Chemotherapy 42, 1-6.

De Clercq, E. (2004). Antiviral drugs in current clinical use. Journal of Clinical Virology 30, 115-133.

Dorwal, D. (2012). Development of UV spectrophotometric method for determination of methyl salicylate in bulk and semisolid. International Journal of Research in Pharmaceutical and Biomedical Sciences 3, 983-986.
Georgetti, S. R., Casagrande, R., Testa Moura-deCarvalho Vicentini, F. T., Verri Jr., W. A. and Fonseca, M. J. V. (2006). Evaluation of the antioxidant activity of soybean extract by different in vitro methods and investigation of this activity after its incorporation in topical formulations. European Journal of Pharmaceutics and Biopharmaceutics 64, 99-106.

Hussin, A., Md. Nor, N. S. and Ibrahim, N. (2013). Phenotypic and genotypic characterization of induced acyclovir-resistant clinical isolates of herpes simplex virus type 1. Antiviral Research 100, 306-313.

Jewers, K., Davis, J. B., Dougan, J., Manchada, A. H., Blunden, G., Kyi, A. and Wetchapinan, S. (1972). Goniothalamin and its distribution in four Goniothalamus species. Phytochemistry 11, 20252030.

Md Nor, N. S. and Ibrahim, N. (2011). Styrylpyrone Derivative of Goniothalamus umbrosus inhibit HSV-1 infection during viral early replication cycle. Antiviral Research 90, A21-A78.

Md Nor. (2015). Antiviral mechanism of styrylpyrone derivative (SPD) compound from Goniothalamus umbrosus against Herpes Simplex Virus type-1. Ph.D Thesis, Universiti Kebangsaan Malaysia, Malaysia.

Moses, M., Md Nor, N. S. and Ibrahim, N. (2014). In vitro virucidal activity of styrylpyrone derivative against herpes simplex virus KOS-1. AIP Conference Proceedings 1614, 562-565.

Mossman, T. (1983). Rapid colorimetric assay for cellular growth and survival applicationn to proliferation and cytotoxicity assays. Journal of Imunological Methods 65, 55-63.

Muller, B. and Krausslich, H. (2009). Antiviral strategies. In: Antiviral Strategies. Krausslich, $H$. and Bartenschlager, R. (eds.). Springer-Verlag, Heidelberg. pp. 10-15.

Ramadan, M. F. and Asker, M. M. S. (2009). Antimicrobial and antiviral impact of novel quercetin enriched lecithin. Journal of Food Biochemistry 33(4), 557-571.

Saijo, M., Suzutani, T., Morikawa, S. and Kurane, I. (2005). Genotypic characterization of the DNA polymerase and sensitivity to antiviral compounds of foscarnet-resistant Herpes Simplex Virus Type 1 (HSV-1) derived from a foscarnet-sensitive HSV-1 strain. Antimicrobial Agents and Chemotherapy 49, 606-611.

Salem, M. L. and Hossain, M. S. (2000). Protective effect of blackseed oil from Nigella sativa against murine cytomegalovirus infection. Journal of Immunopharmacology 22, 729-740.

Souza, T. M. L., De Souza, M. C. B. V., Ferreira, V. F., Santos, C., Carla Veronica, B. M., Isakelly, P., Fontes, C. F. L. and Frugulhetti, I. C. P. P. (2008). Inhibition of HSV-1 replication and HSV DNA polymerase by the chloroxoquinolinic ribonucleoside 6 chloro-1,4-dihydro-4-oxo-1-( $\beta$-d-ribofuranosyl) quinoline-3-carboxylic acid and its aglycone. Antiviral Research 77, 20-27. 